\title{
Model for the Assessment of Seawater Environmental Quality Based on Multiobjective Variable Fuzzy Set Theory
}

\author{
Lina Ke and Huicheng Zhou \\ School of Hydraulic Engineering, Dalian University of Technology, Dalian 116024, China \\ Correspondence should be addressed to Lina Ke; kekesunny@163.com
}

Received 17 February 2013; Accepted 23 April 2013

Academic Editor: Yong Zhang

Copyright ( 2013 L. Ke and H. Zhou. This is an open access article distributed under the Creative Commons Attribution License, which permits unrestricted use, distribution, and reproduction in any medium, provided the original work is properly cited.

\begin{abstract}
With the rapid development of marine economy industry, the activities for exploring and exploiting the marine resources are increasing, and there are more and more marine construction projects, which contribute to the growing trend of eutrophication and frequent occurrence of red tide. Thus, seawater quality has become the topic which the people generally cared about. The seawater quality evaluation could be considered as an analysis process which combined the evaluation indexes with certainty and evaluation factors with uncertainty and its changes. This paper built a model for the assessment of seawater environmental quality based on the multiobjective variable fuzzy set theory (VFEM). The Qingdao marine dumping site in China is taken as an evaluation example. Through the quantitative research of water-quality data from 2004 to 2008, the model is more reliable than other traditional methods, in which uncertainty and ambiguity of the seawater quality evaluation are considered, and trade the stable results as the final results of seawater quality evaluation, which effectively solved the impact of the fuzzy boundary of evaluation standard and monitoring error, is more suitable for evaluation of a multi-index, multilevel, and nonlinear marine environment system and has been proved to be an effective tool for seawater quality evaluation.
\end{abstract}

\section{Introduction}

Since the 1950s, marine environmental quality has been studied by domestic and foreign scholars in detail, and many methods for seawater quality evaluation are available, including the single factor index method [1-3], the fuzzy comprehensive evaluation method [4-6], the BP neural network method [7, 8], the grey clustering method [9], and the support vector machine (SVM) [10], among others. Each of these methods has their own advantages and disadvantages. Seawater quality assessment combines certain evaluation indices and criteria with uncertain evaluation factors and is a complicated process coupling the effects of multiple factors and their content changes. The assessment indices are often variable with fuzzy uncertainty. Commonly, traditional methods of water quality assessment treat the evaluation standard and a reference as a point [11, 12], and hence the application of these methods have some limitations. In recent years, application of fuzzy comprehensive evaluation becomes more and more popular in real cases [13-17], for solving the limitation problem in a classical mathematical model that describes uncertainty with either-or only. In fuzzy sets theory, we use this and that to describe the problems in uncertainty [18], we could solve the problem of fuzzy boundary effectively and monitor errors affecting the evaluation results in environment evaluation. However, the fuzzy comprehensive evaluation method has some uncertainties, and the model is difficult to perform self-adjustment and self-verification. Therefore, to evaluate seawater environment quality scientifically with feasibility, we put forward a new model for assessment of seawater environment quality based on variable fuzzy recognition model and applied it in the assessment of seawater quality status of the Qingdao marine dumping site in China from 2004 to 2008. The results demonstrate that with the method, we can reasonably determine the relative membership degree and the relative membership function of evaluation indices in all levels or intervals of applicable standard and assess the grade of water quality more 
realistically and reasonably, which would be important as a new concept and reference for improving the performance of seawater assessment in China and, potentially, in the world.

\section{Materials and Methods}

2.1. Variable Fuzzy Model for Seawater Quality Evaluations. The comprehensive seawater quality level of an object $u$ is identified according to the standard of $m$ indices and $c$ grades. In the standard interval of each index at level- $h$, point $M_{i h}$ is sure to exist, and thus, the relative membership degree of $M_{i h}$ to level- $h$ is equal to one. The variable $M_{i h}$ is defined as the standard value of index- $i$ at level- $h$.

(1) According to $m$ indices and $c$ grades, determine the attraction domain matrix, $I_{a b}=\left(\left[a_{i h}, b_{i h}\right]\right)$, of the variable set for seawater quality evaluation, range domain matrix, $I_{c d}=\left(\left[c_{i h}, d_{i h}\right]\right)$, and $M_{i h}$ point value matrix. $M_{i h}$ can be determined according to the following formula:

$$
M_{i h}=\frac{c-h}{c-1} a_{i h}+\frac{h-1}{c-1} b_{i h} .
$$

If $h=1$, then $M_{i 1}=a_{i 1}$, if $h=c$, then $M_{i c}=b_{i c}$, and if $h=(c+1) / 2$, then $M_{i l}=\left(a_{i l}+b_{i l}\right) / 2$.

(2) Calculating the relative membership degree matrix: when $x$ falls to the left side of point $M_{i h}$, the relative membership degree model is calculated as follows:

$$
\begin{gathered}
\underset{\sim}{\mu}\left(x_{i j}\right) h=0.5 *\left[1+\left(\frac{x-a}{M_{i h}-a}\right)^{\beta}\right] ; \quad x \in\left[a, M_{i h}\right], \\
\underset{\sim}{\mu A}\left(x_{i j}\right) h=0.5 *\left[1-\left(\frac{x-a}{c-a}\right)^{\beta}\right] ; \quad x \in[c, a] .
\end{gathered}
$$

When $x$ falls to the right side of point $M_{i h}$, the relative membership degree model is calculated as follows:

$$
\begin{gathered}
\stackrel{\sim}{\sim}\left(x_{i j}\right) h=0.5 *\left[1+\left(\frac{x-b}{M_{i h}-b}\right)^{\beta}\right] ; \quad x \in\left[M_{i h}, b\right], \\
\underset{\sim}{\mu A}\left(x_{i j}\right) h=0.5 *\left[1-\left(\frac{x-b}{d-b}\right)^{\beta}\right] ; \quad x \in[b, d]
\end{gathered}
$$

in which $\beta=1$ and the function model is a linear function.

(3) The comprehensive relative membership degree vector of sample $j$ to level $h$ is calculated as follows:

$$
j \mu^{\prime} h=\frac{1}{1+\left\{\sum_{i=1}^{m}[w i(1-\mu \underline{A}(x i j) h)]^{p} / \sum_{i=1}^{m}(w i \mu \underline{A}(x i j) h)^{p}\right\}^{a / p}},
$$

where $\alpha$ is the model optimization criteria parameter, $p$ is the distance parameter, and $\alpha$ and $p$ can have 4 combinations given as follows. (a) When $a=1, p=1$, the model is the fuzzy comprehensive evaluation model:

$$
v_{h}(u)=\sum_{i=1}^{m} w_{i} u_{i h}(u)
$$

(b) When $a=1, p=2$, the model is the TOPSIS model:

$$
v_{h}(u)=\frac{1}{1+\sqrt{\sum_{i=1}^{m}\left[w_{i}\left(1-u_{i h}(u)\right)\right]^{2} / \sum_{i=1}^{m}\left[w_{i} u_{i h}(u)\right]^{2}}} .
$$

(c) When $a=2, p=1$, the model is the activation function model of a neuron:

$$
v_{h}(u)=\frac{1}{1+\left[\left(1-\sum_{i=1}^{m} w_{i} u_{i h}(u)\right) / \sum_{i=1}^{m} w_{i} u_{i h}(u)\right]^{2}} .
$$

(d) When $a=2, p=2$, the model is the fuzzy optimization model:

$$
v_{h}(u)=\frac{1}{1+\sum_{i=1}^{m}\left\{w_{i}\left[1-u_{i h}(u)\right]\right\}^{2} / \sum_{i=1}^{m}\left[w_{i} u_{i h}(u)\right]^{2}} .
$$

In the conditions of fuzzy concept classification, using the principle of the maximum membership degree to identify the level of an object in assessment for seawater quality can easily produce an incorrect final result. The level-characteristic value proposed in the equation by $\mathrm{Chen}$ and $\mathrm{Hu}$ [19] can fully express the whole distribution characteristics of $h$ and $v_{h}(u)$, can make best information of the relative membership degree of level variables $h$ to a certain level, and can be used as the criterion of the variable fuzzy set theory to judge, identify, and determine the level:

$$
H(u)=\sum_{h=1}^{c} v^{0}(u) h
$$

\subsection{Determination of Weight}

2.2.1. Determination of the Experience Weight $w_{1}$ by the Nonstructural Decision-Making Fuzzy Theory Model. The limitation of the AHP model of putting a binary comparison of the element attributes into the comparison of the importance is analyzed, and a nonstructural decision-making fuzzy theory model was presented by Professor Chen [20]. The two adjectives are used to describe the fuzzy boundary values of 0.5 and 1.0 according to their degree of importance, which are equally important and incomparably important, and were further divided into 11 mood operators: "equally," "slightly," "somewhat," "rather," "obviously," "remarkably," "very," "extra," "exceedingly," "extremely" and "incomparably" which represent a different fuzzy scale (Table 1). The relative membership degree of the objective to the importance of the fuzzy concepts is calculated to attain the weight of the objective set. The specific calculation steps are as follows. 
(1) An objective set $P=\left\{p_{1}, p_{2}, \ldots, p_{m}\right\}$ for comparing the importance and build a binary importance sequence matrix $E$ according to the degree of importance of the target elements.

(2) Arrange the sum of $E$ matrix lines from large to small, and obtain the importance sequence of the objective set.

(3) According to the matrix E, make a binary importance judgment by experience.

(4) By the relationships between different mood operators and fuzzy scales, calculate the relative membership degree of the objective to the importance of the fuzzy concepts and attain the nonnormalized weight vector $w_{1}$ according to formula (4):

$$
\varphi_{1 i}=\frac{1-\beta_{1 i}}{\beta_{1 i}}
$$

$\beta_{1 i}$ is the binary importance fuzzy scale value between objective 1 and objective $i ; \varphi_{1 i}$ is the relative membership degree of objective $i$ to the importance.

2.2.2. Determination of the Objective Weight $w_{2}$ by the Standard Level Method of Water Quality. Consider

$$
w_{2}= \begin{cases}\frac{x_{i}}{\bar{S}_{i}}, & x_{i}>\bar{S}_{i}, \quad \bar{S}_{i}=\frac{1}{m} \sum_{j=1}^{m} S_{i j}, \quad m=4 . \\ 1, & x_{i} \leq \bar{S}_{i},\end{cases}
$$

For DO

$$
w_{2}= \begin{cases}1, & x_{i} \geq \bar{S}_{i} \\ \frac{\bar{S}_{i}}{x_{i}}, & x_{i}<\bar{S}_{i} .\end{cases}
$$

In the above formula, $x_{i}$ is the measured value of the $i$ th pollution factor; $S_{i}$ is the standard seawater quality value of the $j$ th pollution factor at the $i$ th level; $\bar{S}_{i}$ is the average seawater quality value of four levels of the $i$ th pollution factor; $n$ is the number of pollution factors; and $m$ is the level number in the seawater quality standard.

2.2.3. Comprehensive Weight. The weight determined by the nonstructural decision-making fuzzy theory model is an experience weight and can easily be influenced by anthropic factors. During the evaluation process, the effect of some indices may be overstated or reduced; the weight determined by the standard level method is a mathematical weight. The relative importance of some indices has not been considered. The two types of weight methods each have certain advantages and limitations.

Here referring to this paper [22], the combination weight is adopted to improve the reliability of weight setting, which combined the binary fuzzy clustering weight with the standard level weight, and the calculation formula is as follows:

$$
w=\alpha w_{1}+(1-\alpha) w_{2} .
$$

In this formula, $w$ is the combinational weight, $w_{1}$ is the experience weight determined by the non-structural decisionmaking fuzzy model, $w_{2}$ is the objective weight determined by the standard level model, $\alpha$ is the sensitivity coefficient with values of $0<a<1$. In general, the range of $a$ is $0.5 \sim 0.7$. To reinforce the importance of the combinational weight, here an intermediate value 0.6 was obtained and was regarded as the sensitivity coefficient of the combinational weight.

\section{Results and Discussion}

The Qingdao marine dumping site was one of the first marine dumping sites for Category III dredged materials specified by the State Oceanic Administration and approved by the State Council since the implementation of the Regulations of the People's Republic of China on Control over Dumping of Wastes in the Ocean. The dumping site is located in the southeast of the Jiaozhou Bay estuary, $6.7 \mathrm{~km}$ from Qingdao, and its area is about $7 \mathrm{~km}^{2}$, extending between $120^{\circ} 18^{\prime} 00^{\prime \prime}$ and $120^{\circ} 20^{\prime} 00^{\prime \prime}$ east longitude and from $35^{\circ} 59^{\prime} 24^{\prime \prime}$ to $35^{\circ} 58^{\prime} 39^{\prime \prime}$ north latitude. This site receives dredged materials primarily from Qingdao port, other small ports, and navigation channels.

From November 1986 to 2009, the dredged materials dumped at this site exceeded a volume of $8.00 \times 10^{7} \mathrm{~m}^{3}$. This sea area is close to the navigation channel, the aquaculture area, and the holiday resort. It is the ecologically sensitive area that is also important for economic development. Therefore, it is important to accurately and timely evaluate the current environmental conditions at the dumping site for preventing ocean dumping from damaging the ecological environment, marine resources, and the submarine landform.

To facilitate comparisons, this study utilized monitoring data (Table 2) of the seawater quality at the Qingdao marine dumping site [23]. In view of the pollution conditions of dredged materials and the present seawater pollution situation at the dumping site $[23,24]$, nine evaluation factors were selected, that is, COD, oils, $\mathrm{DO}$, inorganic nitrogen, $\mathrm{PO}_{4}$ $\mathrm{P}, \mathrm{Cu}, \mathrm{Pb}, \mathrm{Zn}$ and $\mathrm{Cd}$ for the index standards, please see the Seawater Quality Standard (GB 3097-1997). The variable fuzzy model was adopted to evaluate the situation of seawater quality at the Qingdao marine dumping site.

The data from 14 monitoring points (Table 2) in the Qingdao marine dumping site were used to validate the variable fuzzy model. The characteristic value matrix and the index standard value matrix of the seawater quality are established below according to the Seawater Quality Standard (GB 3097-1997) and the seawater quality monitoring data of the 14 sampling points in the Qingdao dumping site [23], that is, $x$ and $y$ : 


$$
\begin{aligned}
& x=\left\{\begin{array}{ccccccccc}
0.655 & 0.051 & 7.678 & 108.500 & 9.050 & 3.183 & 1.553 & 41.425 & 0.176 \\
0.705 & 0.049 & 7.620 & 121.000 & 6.350 & 4.393 & 1.940 & 73.767 & 0.208 \\
\cdots & \cdots & \ldots & \ldots & \ldots & \ldots & \ldots & \ldots & \ldots \\
0.725 & 0.023 & 7.635 & 97.000 & 6.250 & 3.660 & 2.678 & 32.542 & 0.187
\end{array}\right\}^{T} \\
& y=\left\{\begin{array}{ccccccccc}
{[0,2]} & {[0,0.05]} & {[6,12]} & {[0,200]} & {[0,15]} & {[0,5]} & {[0,1]} & {[0,20]} & {[0,1]} \\
{[2,3]} & {[0,0.05]} & {[5,6]} & {[200,300]} & {[15,30]} & {[5,10]} & {[1,5]} & {[20,50]} & {[1,5]} \\
{[3,4]} & {[0.05,0.30]} & {[4,5]} & {[300,400]} & {[15,30]} & {[10,50]} & {[5,10]} & {[50,100]} & {[5,10]} \\
{[4,5]} & {[0.30,0.50]} & {[3,4]} & {[400,500]} & {[30,45]} & {[10,50]} & {[10,50]} & {[100,500]} & {[5,10]} \\
(5, \infty) & (0.5,1) & {[0,3)} & (500,1000) & (45, \infty) & (50, \infty) & (50, \infty) & (500, \infty) & (10, \infty)
\end{array}\right\}^{T} .
\end{aligned}
$$

In reference to the standard seawater quality value and the actual seawater quality conditions at the Qingdao dumping site, the attraction domain matrix, the range domain matrix, and the $M_{i h}$ matrix of the variable fuzzy seawater quality evaluation model were determined. Here, for the oil, $\mathrm{PO}_{4}, \mathrm{Cu}$, and $\mathrm{Cd}$, the standard values of the adjacent level are the same, so the mean value of the two levels was used in the actual classification to further divide the adjacent index levels. For example, for the $\mathrm{PO}_{4}$ index, the standard value of Grade II and Grade III is $0.015 \sim 0.030 \mathrm{mg} / \mathrm{L}$; to facilitate the evaluation, the interval of Grade II was taken as $0.015 \sim 0.0225 \mathrm{mg} / \mathrm{L}$, while the interval of Grade III was taken as $0.0225 \sim 0.030 \mathrm{mg} / \mathrm{L}$. Practice has proved that it has no influence on the evaluation results. $M_{i h}$ can be determined by formula (1).

Therefore, the respective attraction domain matrix, the range domain matrix, and the $M_{i h}$ matrix of the variable fuzzy seawater quality evaluation model are as follows:

$$
\begin{aligned}
& I_{a b}=\left[\begin{array}{ccccccccc}
{[0,2]} & {[0,0.025]} & {[6,7.768]} & {[0,200]} & {[0,15]} & {[0,5]} & {[0,1]} & {[0,20]} & {[0,1]} \\
{[2,3]} & {[0.025,0.05]} & {[5,6]} & {[200,300]} & {[15,22.5]} & {[5,10]} & {[1,5]} & {[20,50]} & {[1,5]} \\
{[3,4]} & {[0.05,0.3]} & {[4,5]} & {[3000,400]} & {[22.5,30]} & {[10,30]} & {[5,10]} & {[50,100]} & {[5.7 .5]} \\
{[4,5]} & {[0.3,0.5]} & {[3,4]} & {[400,500]} & {[30,45]} & {[30,50]} & {[10,50]} & {[100,500]} & {[7.5,10]} \\
{[5,6]} & {[0.5,0.75]} & {[2,3]} & {[500,600]} & {[45,60]} & {[50,70]} & {[50,90]} & {[500,900]} & {[10,14]}
\end{array}\right], \\
& I_{c d}=\left[\begin{array}{ccccccccc}
{[0,3]} & {[0,0.05]} & {[5,7.678]} & {[0,300]} & {[0,22.5]} & {[0,10]} & {[0,5]} & {[0,50]} & {[0,5]} \\
{[0,4]} & {[0,0.3]} & {[4,7.678]} & {[0,400]} & {[0,30]} & {[0,30]} & {[0,10]} & {[0,100]} & {[0,7.5]} \\
{[2,5]} & {[0.025,0.5]} & {[3,6]} & {[200,500]} & {[15,45]} & {[5,50]} & {[1,50]} & {[20,500]} & {[1,10]} \\
{[3,6]} & {[0.05,0.75]} & {[2,5]} & {[300,600]} & {[22.5,60]} & {[10,70]} & {[5,90]} & {[50,900]} & {[5,14]} \\
{[4,6]} & {[0.3,0.75]} & {[2,4]} & {[400,600]} & {[30,60]} & {[30,70]} & {[10,90]} & {[100,900]} & {[7.5,14]}
\end{array}\right]^{T}
\end{aligned}
$$

$$
M_{i h}=\left[\begin{array}{ccccccccc}
0 & 0 & 7.678 & 0 & 0 & 0 & 0 & 0 & 0 \\
2.25 & 0.03125 & 5.75 & 225 & 16.875 & 6.25 & 2 & 27.5 & 2 \\
3.5 & 0.175 & 4.5 & 350 & 26.25 & 20 & 7.5 & 75 & 6.25 \\
4.75 & 0.45 & 3.25 & 475 & 41.25 & 45 & 40 & 400 & 9.375 \\
6 & 0.75 & 2 & 600 & 60 & 70 & 90 & 900 & 14
\end{array}\right]
$$

If $x_{i j}$ is on the left side of $M_{i h}$, select formula (2) to calculate the relative membership degree, otherwise select formula (3) to calculate the relative membership degree.

Based on the consideration of expert opinions, the numerous studies available in the literature [25-29], and the corresponding relationship between tone operators and the fuzzy scale values given in Table 1, the two-dimensional importance comparison matrix of 9 indicators from large to small at a consistent scale $\beta$ can be determined, and the sum of the fuzzy measure values is as follows:

$$
\begin{aligned}
w & =\left(\sum_{t=1}^{m} \beta_{1 t}, \sum_{t=1}^{m} \beta_{2 t}, \ldots, \sum_{t=1}^{m} \beta_{m t}\right) \\
& =(1.99,3.4,1.07,2.58,1.79,2.09,6.86,5.14,1.09) .
\end{aligned}
$$

By normalizing the fuzzy measure values matrix, we obtained the weight of 9 indexes of seawater quality evaluation:

$$
\begin{gathered}
W_{1}=(0.077,0.131,0.041,0.099,0.069, \\
0.080,0.264,0.198,0.042) .
\end{gathered}
$$

Using formulas (11) and (12), the weight $\left(w_{2}\right)$ was obtained as follows:

$$
\begin{gathered}
W_{2}=(0.110,0.109,0.107,0.122,0.112, \\
0.113,0.109,0.109,0.109)
\end{gathered}
$$

According to formula (13), we could obtain the combination weight of 9 indices:

$$
\begin{gathered}
W=(0.090,0.122,0.067,0.108,0.086,0.093, \\
0.202,0.162,0.069) \text {. }
\end{gathered}
$$


Using (4)-(9) to calculate the characteristic level value of sample at the time of $a=1, p=1 ; a=1, p=2 ; a=2$, $p=1 ; a=2, p=2$, and then the final evaluation results were obtained according to the following formula (20), as shown in Table 3:

$$
\begin{array}{ll}
c-0.25 \leq H_{j} \leq c & \text { Corresponds to level } c \\
h-0.25<H_{j} \leq h+0.25 & \begin{array}{l}
\text { Corresponds to level } h, \\
h=1,2, \ldots, c-1,
\end{array} \\
h+0.25<H_{j}<h+0.75 & \begin{array}{l}
\text { Between level } h \text { and } h+1, \\
\text { tending toward one of the } \\
\text { two levels. }
\end{array}
\end{array}
$$

As shown in Table 3, the evaluation results of 14 sampling points based on the variable fuzzy evaluation model are more consistent with the evaluation results based on a BP network, fuzzy comprehensive evaluation method, and fuzzy genetic neural network method, and only slight differences between the evaluation results of the variable fuzzy evaluation model and the results of other models were found in few sampling points. With the variation of $(a, p)$ parameters in variable fuzzy recognition model, the characteristic level value of four different mathematical models at the sampling points remained within a small fluctuation range. Furthermore, compared with other evaluation methods, the variable fuzzy evaluation model can provide a more accurate position of the water quality level. The conditions of seawater quality at sampling points can be accurately differentiated according to the characteristic level values. The evaluation results by the variable fuzzy evaluation method at sampling points 2 and 5 are slightly inconsistent with the results by the other methods. Now, differences between variable fuzzy recognition model and fuzzy comprehensive evaluation model at those points of discrepancy are analyzed further.

For sampling point 2, the evaluation result based on the variable fuzzy evaluation model is between I and II, tending toward II, while the result based on the BP network and fuzzy genetic neural network is Grade III, and the result of fuzzy comprehensive evaluation method is Grade II. According to analyzing the original data of point 2 , the values of COD, $\mathrm{DO}$, inorganic nitrogen, $\mathrm{PO}_{4}-\mathrm{P}, \mathrm{Cu}$ and $\mathrm{Cd}$ are $0.705 \mathrm{mg} / \mathrm{L}$, $7.620 \mathrm{mg} / \mathrm{L}, 121 \mu \mathrm{g} / \mathrm{L}, 6.35 \mu \mathrm{g} / \mathrm{L}, 4.393 \mu \mathrm{g} / \mathrm{L}$ and $0.208 \mu \mathrm{g} / \mathrm{L}$, respectively, which fall within the range of Grade I; the concentrations of $\mathrm{Pb}$ and $\mathrm{Cd}$ are $1.94 \mu \mathrm{g} / \mathrm{L}$ and $73.767 \mu \mathrm{g} / \mathrm{L}$, respectively, which fall within the range of Grade II; and only the content of oil, is $0.049 \mathrm{mg} / \mathrm{L}$, which is close to the Grade III standard, but still falls within the range of Grade I or Grade II. Based on the actual seawater quality conditions at the Qingdao dumping site, oil, $\mathrm{Pb}$ and $\mathrm{Zn}$ strongly influence the seawater quality of Qingdao dumping site. The weights of these indices are $0.122,0.202$ and 0.162 , respectively, accounting for $48.6 \%$ of the total weight, so the classification result of between Grade I and Grade II, tending toward Grade II, is reasonable. The average characteristic level value by the variable fuzzy evaluation model was 1.66, and this evaluation result is more credible than the results of other models, more consist with the actual conditions of point 2. The results of BP network, fuzzy genetic neural network, and fuzzy comprehensive valuation method were Grade II or Grade III, overemphasizing a few pollution heavy factors and causing the evaluation results too high. Similarly, the situation of point 5 is similar to point 2 .

Analyzing the causes of the differences between BP network, fuzzy comprehensive evaluation method, fuzzy genetic neural network evaluation method, and variable fuzzy evaluation model in Table 3 , fuzzy comprehensive evaluation method determines the water quality level on the basis of the maximum membership degree principle, thus, when the membership degree of the water quality at a level site does not differ considerably from the adjacent level (e.g., the membership degrees attached to Grade I, Grade II, Grade III, and Grade IV are 0, 0.34, 0.37 and 0.29, resp.), many important information may be lost, therefore, which often leads to the final evaluation results incorrect. BP neural network and genetic neural network adopt feed-forward networks, and their network structure is determined by experience, which always shows a great deal of randomness. As a result, it is sometimes possible to obtain a very small global optimum, causing the misjudgment of the final result.

This paper combines the monitoring values of seawater quality indicators with the national standard to build a seawater quality evaluation model in variable fuzzy recognition model, to deal with greater subjectivity problems of water quality evaluation with limited data. To a certain extent, we will measure the ambiguity and uncertainty of water quality evaluation objectively and increase the credibility of the rank of a sample point [30].

The method of the seawater quality evaluation model based on variable vague set theory in this paper is able to combine linear model with nonlinear model through changes of the variable model parameters $(a, p)$. This method not only avoids the instability of evaluation results caused by the single model but also can reflect the difference of the membership degree of the adjacent water level and finally take the stable level value as the final evaluation results of seawater environment. It can arrange the situation of water environment quality of various samples and clearly determine the water quality status that makes the evaluation results more trustworthy. According to the linear or nonlinear feature of the evaluation objects, seawater quality evaluation based on variable fuzzy recognition model can select variable models with the changes of variable model parameters $(a, p)$ and combine the linear features with the nonlinear features of the evaluation objective, which weakened the influence of the index weight on the final results. It makes the model more flexible and accurate and avoids "over-fitting" because the neural network structure is too large. It also ensures that the model has better generalization ability and predictive ability.

However, for variable fuzzy recognition model, the rational weight setting is still an important factor to determine the reliability of the evaluation results. Due to cross-iteration of the parameters of variable fuzzy recognition model and the variability of indicators weight vector, it is very important to reasonably set the indicator weight according to the nature of a real case and the importance of actual decision objective in practice.

We use weight-determination method of the comprehensive weight which combines the subjective nonstructural 
TABLE 1: Corresponding relationship between the tone operator and fuzzy scale values.

\begin{tabular}{lccccc}
\hline Tone operator & Equally & Slightly & Somewhat & Rather & Obviously \\
Fuzzy scale & 0.50 & 0.55 & 0.60 & 0.65 & 0.70 \\
\hline Tone operator & Very & Extra & Exceedingly & Extremely & Incomparably \\
Fuzzy scale & 0.80 & 0.85 & 0.90 & 0.95 & 1.00 \\
\hline
\end{tabular}

TABLE 2: Monitoring results regarding seawater quality in the Qingdao dumping site in 2003.

\begin{tabular}{lccccccccc}
\hline Sampling point & COD & OIL & DO & Inorganic nitrogen & $\mathrm{PO}_{4}-\mathrm{P}$ & $\mathrm{Cu}$ & $\mathrm{Pb}$ & $\mathrm{Zn}$ & $\mathrm{Cd}$ \\
\hline Q1 & 0.655 & 0.051 & 7.678 & 108.500 & 9.050 & 3.183 & 1.553 & 41.425 & 0.176 \\
Q2 & 0.705 & 0.049 & 7.620 & 121.000 & 6.350 & 4.393 & 1.940 & 73.767 & 0.208 \\
Q3 & 0.680 & 0.027 & 7.612 & 131.000 & 8.100 & 4.768 & 4.133 & 38.775 & 0.378 \\
Q4 & 0.735 & 0.034 & 7.567 & 102.500 & 8.150 & 4.023 & 1.228 & 29.725 & 0.130 \\
Q5 & 0.700 & 0.034 & 7.502 & 101.500 & 6.550 & 5.982 & 2.493 & 57.383 & 0.226 \\
Q6 & 0.750 & 0.029 & 7.553 & 88.000 & 6.550 & 3.475 & 2.298 & 49.400 & 0.286 \\
Q7 & 0.935 & 0.100 & 7.635 & 128.500 & 6.300 & 3.265 & 2.867 & 45.925 \\
Q8 & 0.835 & 0.049 & 7.635 & 122.000 & 7.900 & 4.393 & 1.522 & 33.958 & 0.193 \\
Q9 & 0.600 & 0.062 & 7.519 & 97.500 & 5.950 & 3.143 & 2.317 & 39.675 & 0.201 \\
Q10 & 0.585 & 0.018 & 7.572 & 92.000 & 5.900 & 4.957 & 1.253 & 27.350 & 0.143 \\
Q11 & 0.640 & 0.024 & 7.594 & 97.000 & 6.850 & 3.407 & 2.218 & 35.150 & 0.154 \\
Q12 & 0.670 & 0.028 & 7.676 & 84.500 & 6.100 & 4.517 & 2.192 & 41.200 & 0.188 \\
Q13 & 0.655 & 0.021 & 7.517 & 83.500 & 4.850 & 6.967 & 2.670 & 32.792 & 0.248 \\
Q14 & 0.725 & 0.023 & 7.635 & 97.000 & 6.250 & 3.660 & 2.678 & 32.542 & 0.187 \\
\hline
\end{tabular}

The units for COD, oil and $\mathrm{DO}$ are $\mathrm{mg} / \mathrm{L}$; the units for inorganic nitrogen, $\mathrm{PO}_{4}-\mathrm{P}, \mathrm{Cu}, \mathrm{Pb}, \mathrm{Zn}$ and $\mathrm{Cd}$ are $\mu \mathrm{g} / \mathrm{L}$.

decision-making fuzzy weights with the objective standard level weights and provide a reference for weight setting. In the future, how to set index weight more reasonably in actual marine environment evaluation and how to determine the level of seawater quality according to the characteristic level values will be studied to improve the application of multitarget variable fuzzy recognition model for seawater quality evaluation. Each water quality evaluation method owns different emphases. Variable fuzzy recognition model can combine the linear features with the nonlinear features of the evaluation objective and provide a reference for the multi-objective decision solutions and can be promoted for the evaluation of other multi-index, multilevel, and nonlinear systems.

Using the monitoring data of the seawater quality at Qingdao dumping site (1985-2003), the comprehensive situation of Qingdao dumping site (1985-2003) is evaluated by variable fuzzy comprehensive evaluation model. The evaluation results are shown in Table 4. From Table 4, we can see that the results of seawater quality in the Qingdao dumping site all satisfy the standard of Grade II specified by the Sea Water Quality Standard (GB3097-1997). In 1997 and 2003, the seawater quality of Qingdao dumping site was rather poor and the characteristic level values were 1.59 and 1.64 , respectively, which is within the range of Grade II. In other years, the water quality of Qingdao dumping site was satisfactory and met the standard of Grade I. From 1998 to 2003, the order of seawater quality was as follows: $2002>2000$ $>1985>1991>1997>2003$. Overall, the seawater quality of the Qingdao dumping area presents a drop-rise-drop trend.
From 1985, the seawater quality of the Qingdao dumping area started to decline. In 1997, it reached a low point, and the characteristic level value of the Qingdao dumping area was only 1.59 , which only corresponded to the standard of Grade II. From 2000, the seawater quality of the Qingdao dumping area tended to improve. However, in 2003, the seawater quality began to deteriorate again, and the characteristic level value of the Qingdao dumping area in 2003 was 1.64, which was the worst among the seawater quality situation of the examined years. The major impact factors affecting the seawater quality of the Qingdao dumping area are heavy metals $\mathrm{Pb}, \mathrm{Zn}$ and oils; $\mathrm{Pb}$ is especially the most serious factor for the seawater quality of the Qingdao dumping area. From 1985 to 2003, the content of $\mathrm{Pb}$ is always within the range of Grade II or Grade III; only in 2000, the content of Pb is satisfied with the standard of Grade I. Secondly, the more serious pollutants are oils and Zn. In 1997, the content of oil exceeded the standard of Grade II 0.49 times. The dumped dredged materials are the primary cause affecting the seawater quality of this area, and the wastes dumped into the sea are mainly the dredged materials of Grade III. In these dredged materials, there are a number of pollutants which may affect the marine environment of the Qingdao dumping area, such as $\mathrm{Pb}, \mathrm{Zn}$, oils, and the compounds of other elements. These pollutants are transformed into harmful substances through chemical reactions and biological reactions, which affected the seawater environment of the Qingdao dumping area. Nevertheless, compared with the environmental conditions of the time when the dumping area was delimited, the environmental conditions of the dumping area have essentially 
TABLE 3: Comparison of the comprehensive seawater quality evaluation results.

\begin{tabular}{|c|c|c|c|c|c|c|c|c|c|}
\hline \multirow{2}{*}{$\begin{array}{l}\text { Point } \\
\text { Number }\end{array}$} & \multirow[b]{2}{*}{$\begin{array}{l}\alpha=1 \\
p=1\end{array}$} & \multirow[b]{2}{*}{$\begin{array}{l}\alpha=1 \\
p=2\end{array}$} & \multicolumn{4}{|c|}{ Variable fuzzy evaluation method } & \multirow{2}{*}{$\begin{array}{l}\text { Fuzzy } \\
\text { comprehensive } \\
\text { evaluation }\end{array}$} & \multirow[b]{2}{*}{ BP neural Network } & \multirow[b]{2}{*}{$\begin{array}{l}\text { Fuzzy genetic } \\
\text { neural Network }\end{array}$} \\
\hline & & & $\begin{array}{l}\alpha=2 \\
p=1\end{array}$ & $\begin{array}{l}\alpha=2 \\
p=2\end{array}$ & $\begin{array}{c}\text { Average } \\
\text { value }\end{array}$ & Evaluation grade & & & \\
\hline Q1 & 1.464 & 1.593 & 1.309 & 1.471 & 1.46 & $\begin{array}{l}\text { Between I and II, } \\
\text { tending toward I }\end{array}$ & Grade II & Grade II & Grade II \\
\hline Q2 & 1.645 & 1.894 & 1.327 & 1.762 & 1.66 & $\begin{array}{l}\text { Between I and II, } \\
\text { tending toward II }\end{array}$ & Grade II & Grade III & Grade III \\
\hline Q3 & 1.597 & 1.761 & 1.504 & 1.694 & 1.64 & $\begin{array}{l}\text { Between I and II, } \\
\text { tending toward II }\end{array}$ & Grade II & Grade II & Grade II \\
\hline Q4 & 1.354 & 1.427 & 1.231 & 1.357 & 1.34 & $\begin{array}{l}\text { Between I and II, } \\
\text { tending toward I }\end{array}$ & Grade I & Grade II & Grade I \\
\hline Q5 & 1.614 & 1.823 & 1.465 & 1.707 & 1.65 & $\begin{array}{l}\text { Between I and II, } \\
\text { tending toward II }\end{array}$ & Grade II & Grade III & Grade III \\
\hline Q6 & 1.492 & 1.705 & 1.304 & 1.553 & 1.51 & $\begin{array}{l}\text { Between I and II, } \\
\text { tending toward II }\end{array}$ & Grade II & Grade II & Grade II \\
\hline Q7 & 1.636 & 1.802 & 1.491 & 1.716 & 1.66 & $\begin{array}{l}\text { Between I and II, } \\
\text { tending to II }\end{array}$ & Grade II & Grade II & Grade II \\
\hline Q8 & 1.451 & 1.539 & 1.370 & 1.497 & 1.46 & $\begin{array}{l}\text { Between I and II, } \\
\text { tending toward I }\end{array}$ & Grade I & Grade II & Grade II \\
\hline Q9 & 1.512 & 1.645 & 1.399 & 1.586 & 1.54 & $\begin{array}{l}\text { Between I and II, } \\
\text { tending toward II }\end{array}$ & Grade II & Grade II & Grade II \\
\hline Q10 & 1.273 & 1.352 & 1.124 & 1.229 & 1.24 & Grade I & Grade I & Grade I & Grade I \\
\hline Q11 & 1.402 & 1.507 & 1.309 & 1.510 & 1.43 & $\begin{array}{l}\text { Between I and II, } \\
\text { tending toward I }\end{array}$ & Grade I & Grade II & Grade II \\
\hline Q12 & 1.463 & 1.611 & 1.348 & 1.538 & 1.49 & $\begin{array}{l}\text { Between I and II, } \\
\text { tending toward I }\end{array}$ & Grade I & Grade II & Grade II \\
\hline Q13 & 1.476 & 1.552 & 1.453 & 1.602 & 1.52 & $\begin{array}{l}\text { Between I and II, } \\
\text { tending toward II }\end{array}$ & Grade I & Grade II & Grade II \\
\hline Q14 & 1.421 & 1.529 & 1.346 & 1.557 & 1.46 & $\begin{array}{l}\text { Between I and II, } \\
\text { tending toward I }\end{array}$ & Grade I & Grade II & Grade II \\
\hline
\end{tabular}

TABLE 4: Results of the variable fuzzy comprehensive evaluation of seawater quality in the Qingdao dumping area (1985-2003).

\begin{tabular}{ccccccccccccc}
\hline Year & COD & OIL & DO & Inorganic nitrogen & $\mathrm{PO}_{4}-\mathrm{P}$ & $\mathrm{Cu}$ & $\mathrm{Pb}$ & $\mathrm{Zn}$ & $\mathrm{Cd}$ & \multicolumn{2}{c}{$\begin{array}{c}\text { Variable fuzzy evaluation model } \\
\text { Average }\end{array}$} \\
\hline 1985 & 0.45 & 0.038 & 8.73 & 1.26 & 0.31 & 0.49 & 4.13 & 2.715 & 0.13 & 1.30 & $\mathrm{I}$ \\
1991 & 0.89 & 0.015 & 7.86 & 25.9 & 6.82 & 0.36 & 5.7 & 9.8 & 0.17 & 1.33 & $\mathrm{I}$ \\
1997 & 0.65 & 0.0745 & 7.76 & 77.3 & 14.96 & 4.74 & 1.28 & 42.5 & 0.07 & 1.59 & $\mathrm{I}$ \\
2000 & 1.54 & 0.021 & 9.17 & 94.42 & 15.75 & 2.98 & 0.86 & 13.7 & 0.18 & 1.14 & $\mathrm{I}$ \\
2002 & 0.48 & 0.024 & 7.99 & 65.7 & 6.5 & 2.04 & 1.49 & 11.16 & 0.28 & 1.11 & $\mathrm{I}$ \\
2003 & 0.72 & 0.039 & 7.64 & 102 & 6.9 & 4.30 & 2.25 & 41.54 & 0.19 & 1.64 & $\mathrm{II}$ \\
\hline
\end{tabular}

remained unchanged. The benthic community structure in the dumping area has not undergone any significant changes due to the dumping of dredged materials. The dumped wastes of the Qingdao dumping area are somewhat controlled within the predicted management, and the dumping of dredged materials has no impact on the offshore marine environment; the basic function of the ocean dumping area is still to be maintained.

\section{Conclusion}

We build a seawater environmental quality assessment model based on variable fuzzy recognition model, in which uncertainty and ambiguity of the seawater quality evaluation are considered, and the monitoring values of seawater quality evaluation indicators and the standard value of seawater quality are combined. Through the application of this model for the Qingdao marine dumping site water quality evaluation and comparison in performance with other models, the model is proved to be an effective tool for seawater quality evaluation. The following conclusions can be drawn.

(1) Seawater environmental quality assessment model based on variable fuzzy recognition model considers the uncertainty and ambiguity involved in the seawater quality evaluation, combines monitoring values of seawater quality evaluation indicators and 
the standard value of seawater quality, and selects the right variable model of the different parameters according to the linear or nonlinear features of the evaluation objects. Therefore, the method is more flexible than other models, and the evaluation results are more stable. It can arrange the situation of water environment quality of various samples and clearly determine the water quality status that makes the evaluation results more credible; therefore, it is more suitable for evaluation of a multi-index, multi-level, and nonlinear marine environment system.

(2) Different indices in different seawater environments have different effects on the evaluation results of seawater quality. In this paper, weight-determination method of the comprehensive weight which combines the subjective nonstructural decision-making fuzzy weights with the objective standard level weights and provides a reference for weight setting. When the evaluation model is applied to other applications, it is necessary to set the index weight reasonably according to the specific conditions of seawater quality evaluation.

(3) In the future, how to determine the level of seawater quality according to the characteristic level values is an important part, which needs to be improved in the application of a multitarget variable fuzzy recognition model for seawater quality evaluation.

\section{References}

[1] P. M. Chapman and F. Wang, "Assessing sediment contamination in estuaries," Environmental Toxicology and Chemistry, vol. 20, no. 1, pp. 3-22, 2001.

[2] A. N. Papanicolaou, A. Bdour, N. Evangelopoulos, and N. Tallebeydokhti, "Watershed and instream impacts on the fish population in the South Fork of the Clearwater River, Idaho," Journal of the American Water Resources Association, vol. 39, no. 1, pp. 191-203, 2003.

[3] N. Fierer, J. L. Morse, S. T. Berthrong, E. S. Bernhardt, and R. B. Jackson, "Environmental controls on the landscape-scale biogeography of stream bacterial communities," Ecology, vol. 88, no. 9, pp. 2162-2173, 2007.

[4] K. O. Adebowale, F. O. Agunbiade, and B. I. Olu-Owolabi, "Fuzzy comprehensive assessment of metal contamination of water and sediments in Ondo Estuary, Nigeria," Chemistry and Ecology, vol. 24, no. 4, pp. 269-283, 2008.

[5] J. Wang, X. Lu, J. Tian, and M. Jiang, "Fuzzy synthetic evaluation of water quality of Naoli river using parameter correlation analysis," Chinese Geographical Science, vol. 18, no. 4, pp. 361368, 2008.

[6] X. L. Wang, T. Li, H. Yang et al., "Fuzzy comprehensivequantifying assessment in analysis of waterquality: a case study in Lake Honghu, China," Environmental Engineering Science, vol. 26, no. 2, pp. 451-458, 2009.

[7] L. Z. Xu, X. P. Ma, Z. Lin et al., "Assessment method for water quality by multi-source information fusion based on BP neural networks and evidence theory," Dynamics of Continuous Discrete and Impulsive Systems B, vol. 2, pp. 520-523, 2005.

[8] Z. H. Guo, J. Wu, H. Y. Lu, and J. Z. Wang, "A case study on a hybrid wind speed forecasting method using BP neural network," Knowledge-Based Systems, vol. 24, no. 7, pp. 10481056, 2011.

[9] C. M. Mi, S. F. Liu, Y. Dang et al., "Study on 2-tuple linguistic assessment method based on grey clustering," Journal of Grey System, vol. 19, no. 3, pp. 257-268, 2007.

[10] J. Cao, H. Hu, S. Qian, and K. Xu, "Research on aggregative index number method in water quality assessment based on SVM," in Proceedings of the 9th International Conference on Electronic Measurement and Instruments (ICEMI'09), pp. 47874791, August 2009.

[11] L. Cea, M. Bermúdez, and J. Puertas, "Uncertainty and sensitivity analysis of a depth-averaged water quality model for evaluation of Escherichia coli concentration in shallow estuaries," Environmental Modelling \& Software, vol. 26, no. 12, pp. 15261539, 2011.

[12] M. T. Bhatti and M. Latif, "Assessment of water quality of a river using an indexing approach during the low-flow season," Irrigation and Drainage, vol. 60, no. 1, pp. 103-114, 2011.

[13] N. B. Chang, H. W. Chen, and S. K. Ning, "Identification of river water quality using the fuzzy synthetic evaluation approach," Journal of Environmental Management, vol. 63, no. 3, pp. 293305, 2001.

[14] C. Ren, C. Li, K. Jia, S. Zhang, W. Li, and Y. Cao, "Water quality assessment for Ulansuhai Lake using fuzzy clustering and pattern recognition," Chinese Journal of Oceanology and Limnology, vol. 26, no. 3, pp. 339-344, 2008.

[15] J. H. Kim, C. M. Choi, S. B. Kim, and S. K. Kwun, "Water quality monitoring and multivariate statistical analysis for rural streams in South Korea," Paddy and Water Environment, vol. 7, no. 3, pp. 197-208, 2009.

[16] L. Liu, J. Zhou, X. An, Y. Zhang, and L. Yang, "Using fuzzy theory and information entropy for water quality assessment in Three Gorges region, China," Expert Systems with Applications, vol. 37, no. 3, pp. 2517-2521, 2010.

[17] D. R. Pathak and A. Hiratsuka, "An integrated GIS based fuzzy pattern recognition model to compute groundwater vulnerability index for decision making," Journal of Hydro-Environment Research, vol. 5, no. 1, pp. 63-77, 2011.

[18] S. Y. Chen, M. Li, and S. Y. Wang, "Rationality analysis and application test of variable fuzzy clustering iterative model," Journal of Dalian University of Technology, vol. 49, no. 6, pp. 932936, 2009.

[19] S. Y. Chen and J. M. Hu, "Variable fuzzy assessment method and its application in assessing water resources carrying capacity," Journal of Hydraulic Engineering, vol. 37, no. 3, pp. 264-277, 2006.

[20] S. Y. Chen, The System Fuzzy Decision Theory and Application, Dalian University of Technology Press, Liaoning China, 1994.

[21] R. R. Zhou, Research on Total Amount Control for Jiaozhou Bay Near Shore Area Pollution Based on ANN and Genetic Algorithms, Ocean University of China, QingDao, China, 2009.

[22] J. Jin, H. Huang, and Y. Wei, "Comprehensive evaluation model for water quality based on combined weights," Journal of Hydroelectric Engineering, vol. 23, no. 3, pp. 13-19, 2004.

[23] L. Zheng, W. L. Cui, Y. Jia et al., "Evaluation on seawater quality by fuzzy comprehensive evaluation method in Qingdao dumping area," Marine Environmental Science, vol. 26, no. 1, p. 4, 2007 (Chinese).

[24] J. Yin, "On the management of marine dumping ground-taking the third category dredged material marine dumping ground outside the Jiaozhou bay, Qingdao as an example," Coastal Engineering, vol. 20, no. 1, p. 4, 2001 (Chinese). 
[25] X. G. Li, J. M. Song, N. Li et al., "Source and biogeochemical characteristics of nitrogen and phosphorusin Jiaozhou Bay sediments," Oceanologia et Limnologia Sinaca, vol. 36, no. 6, pp. 562-571, 2005 (Chinese).

[26] Y. Li, Z. M. Yu, X. H. Cao et al., "Distribution and enrichment of heavy metals in surface sediments of Jiaozhou Bay," Oceanologia et Limnologia Sinaca, 2005.

[27] L. Wan, N. Wang, Q. Li et al., "Distribution of dissolved metals in seawater of Jinzhou Bay, China," Environmental Toxicology and Chemistry, vol. 27, no. 1, pp. 43-48, 2008.

[28] Z. G. Dong, A. G. Lou, and L. W. Cui, "Assessment of eutrophication of Jiaozhou Bay," Marine Sciences, vol. 34, no. 12, pp. 3639, 2010.

[29] L. Q. Ma, Y. Li, Y. J. Zhao, S. Peng, and Q. Zhou, “Temporal and spatial trends of total petroleum hydrocarbons in the seawater of Bohai Bay, China from 1996 to 2005," Marine Pollution Bulletin, vol. 60, no. 2, pp. 238-243, 2010.

[30] D. Wang, V. P. Singh, and Y. Zhu, "Hybrid fuzzy and optimal modeling for water quality evaluation," Water Resources Research, vol. 43, no. 5, Article ID W05415, 2007. 


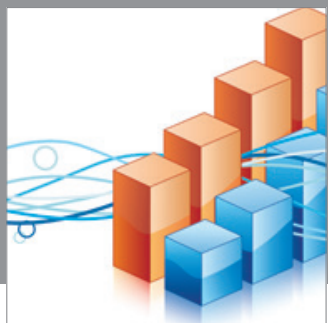

Advances in

Operations Research

mansans

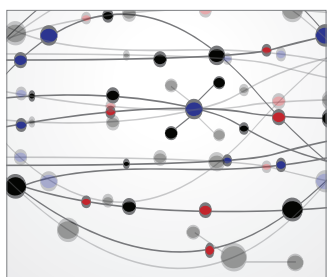

The Scientific World Journal
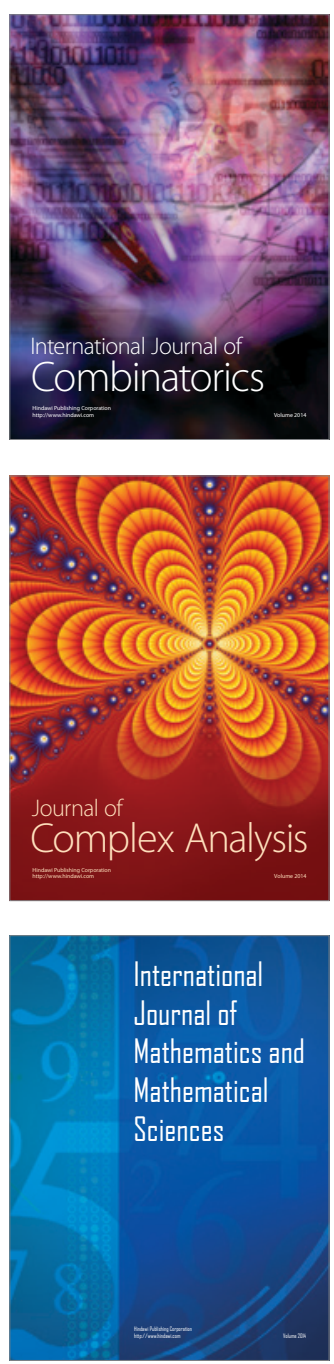
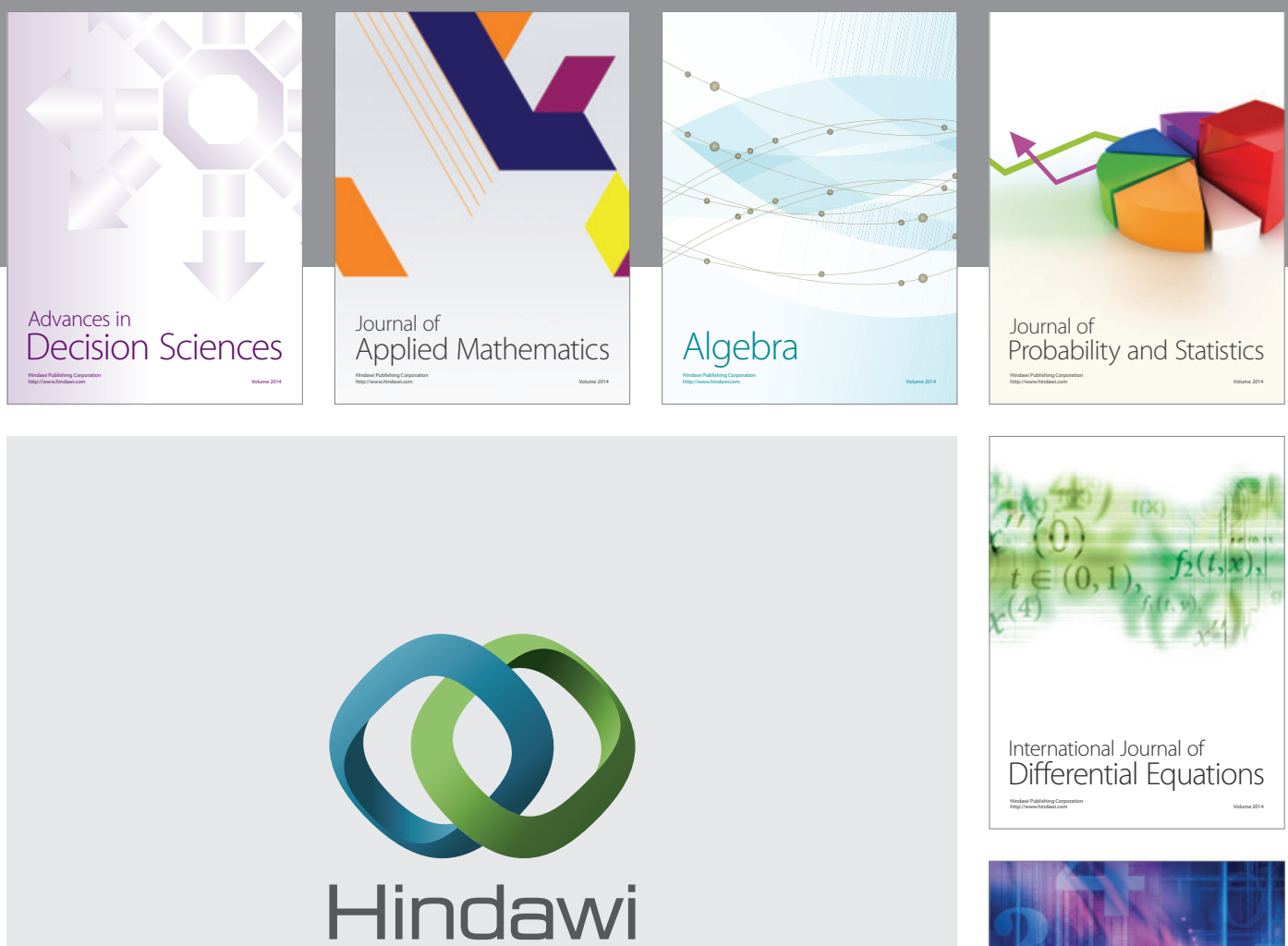

Submit your manuscripts at http://www.hindawi.com
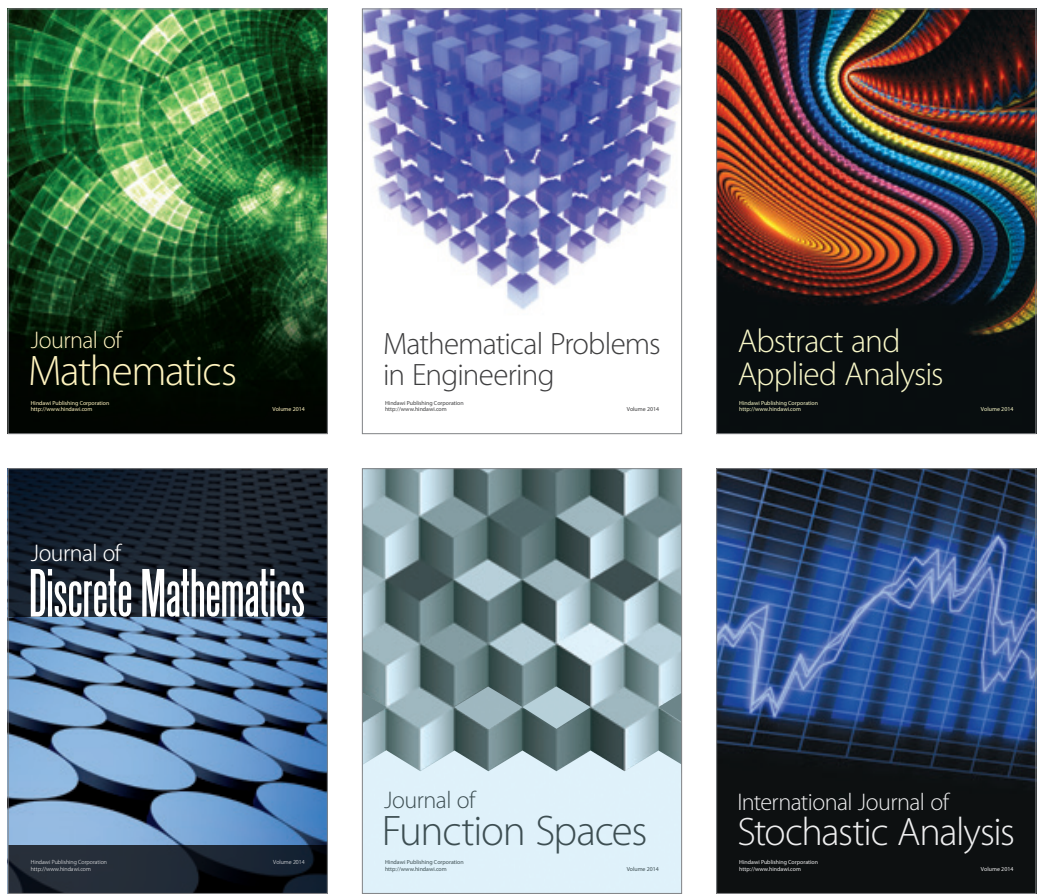

Journal of

Function Spaces

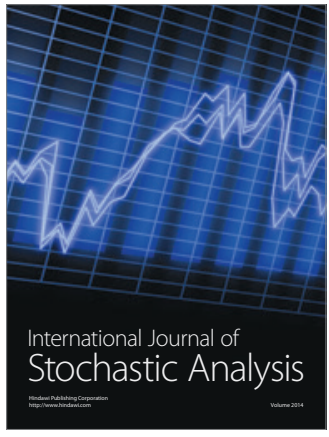

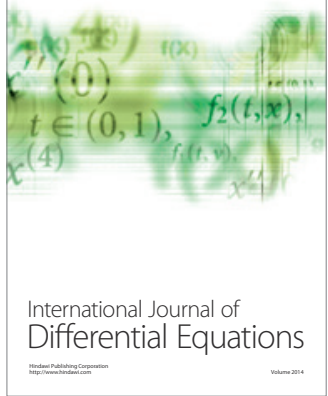
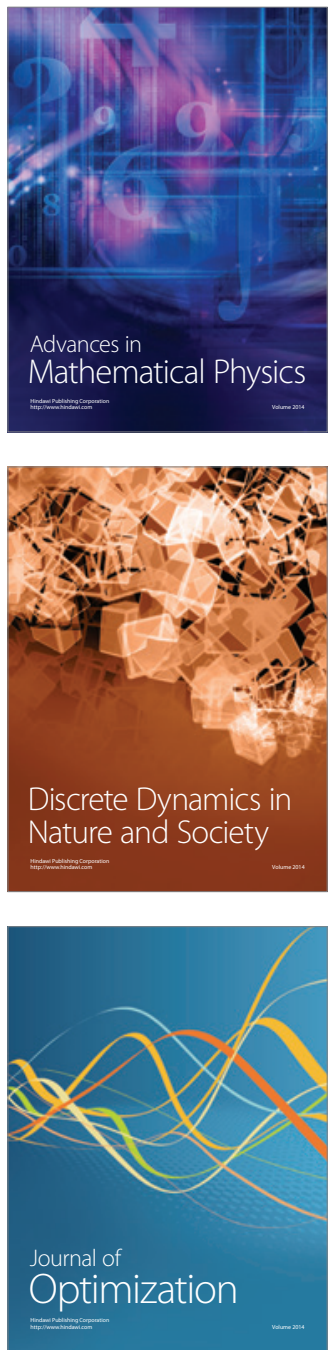